\title{
Goat Acetyl-Coenzyme A Carboxylase $\alpha$ : Molecular Characterization, Polymorphism, and Association with Milk Traits
}

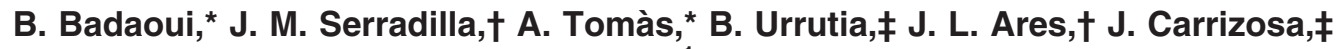 \\ A. Sànchez, ${ }^{*}$ J. Jordana, ${ }^{*}$ and M. Amills ${ }^{* 1}$ \\ *Departament de Ciència Animal, Facultat de Veterinària, Universitat Autònoma de Barcelona, Bellaterra 08193, Spain \\ †Departamento de Producción Animal, Campus de Rabanales, Universidad de Córdoba, 14071 Córdoba, Spain \\ łInstituto Murciano de Investigación y Desarrollo Agrario y Alimentario (IMIDA), Estación Sericícola, La Alberca, Murcia, Spain
}

\section{ABSTRACT}

Acetyl-coenzyme A carboxylase $\alpha$ (ACACA), the major regulatory enzyme of fatty acid biosynthesis, catalyzes the conversion of acetyl-CoA to malonyl-CoA. We have sequenced $5.5 \mathrm{~kb}$ of the goat ACACA cDNA in 18 individuals. The translated cDNA sequence encodes $1,832 \mathrm{AA}$ and shares a high AA identity (99\%) with the ovine and bovine ACACA orthologous sequences. One silent single nucleotide polymorphism was identified at exon 45 (C5493T). The genotyping of this polymorphism in 4 goat breeds, Murciano-Granadina, Teramana, Majorera, and Malagueña, showed that it was segregating in all 4 breeds at variable frequencies. In addition, a mixed animal model was used to evaluate the association of C5493T genotypes with milk traits. Results from this study show that the C5493T mutation was suggestively associated with fat yield, lactose content, and somatic cell count.

Key words: goat, acetyl-CoA carboxylase, polymorphism, milk trait

\section{INTRODUCTION}

Acetyl-coenzyme A carboxylases $\alpha$ (ACACA) and $\beta$ (ACACB) catalyze the formation of malonyl-coenzyme $\mathrm{A}$ and hence, regulate fatty acid biosynthesis and $\beta$ oxidation. In mammals, the ACACA enzyme resides in the cytosol and carries out the ATP-dependent carboxylation of acetyl-CoA to form malonyl-CoA, a key committed step in the biosynthesis of long-chain fatty acids (Cronan and Waldrop, 2002). In contrast, ACACB is a mitochondrial enzyme that, through the synthesis of malonyl-CoA, modulates fatty acid oxidation via inhibition of fatty acid transport to the mitochondria (Ramsay et al., 2001).

The complete sequence of the bovine ACACA cDNA was reported by Mao et al. (2001). This sequence is

Received April 21, 2006.

Accepted July 20, 2006

${ }^{1}$ Corresponding author: Marcel.Amills@uab.es
$7,041 \mathrm{bp}$, maps to chromosome 19 , and encodes a protein with a high AA similarity to those of sheep, human, rat, and chicken (Mao et al., 2001). There are 2 alternative translational start codons that map to exons 5 and 5A. Transcription of the bovine ACACA gene is regulated in a tissue-specific fashion by 4 promoters (Barber et al., 2005). These promoters are named PI and PIa, which are mostly expressed in the central nervous system and white adipose tissue, respectively; PII, with an ubiquitous pattern of tissue expression in all mammalian species; and PIII, which has been found in human and ruminants, and which resides downstream from exon 5 (Barber et al., 2005). In sheep, the sequence and genomic organization of the ACACA gene is very similar to that reported in cattle (Barber and Travers, 1995). In the ovine mammary gland, expression of the PIII transcript is induced 15-fold throughout lactation, suggesting that this isozyme is important for the mammary-specific control of lipogenesis and lipid secretion during lactation (Barber and Travers, 1998). Moioli et al. (2005) described 3 single nucleotide polymorphisms (SNP) in the PIII promoter of the sheep ACACA gene that segregated in several Italian breeds. Interestingly, the Sarda breed, which has been strongly selected for milk production, had a clearly different allelic frequency distribution compared with other local Italian breeds.

The essential role of $A C A C A$ in milk fatty acid metabolism makes this gene an interesting candidate for explaining and interpreting the influence of genetic variation on milk traits in goats. So far, the sequence of the caprine $A C A C A$ gene has not been properly characterized, although a partial sequence $(0.76 \mathrm{~kb})$ has been submitted to Genbank (GenBank accession no. Z17803; Travers and Barber, 1993). The main objective of this work was to sequence the ACACA coding region in several individuals with the aim of identifying polymorphisms that might be used to evaluate the association of $A C A C A$ genotypes with milk traits.

\section{MATERIALS AND METHODS}

\section{Animal Material and Recording of Phenotypic Traits}

One hundred thirty Murciano-Granadina goats, raised under semiextensive management conditions in 
Table 1. Primers used for the amplification of the goat ACACA cDNA with their targets and annealing temperatures (Tann) ${ }^{1}$

\begin{tabular}{|c|c|c|}
\hline Target & Primer name and sequence & $\begin{array}{l}\text { Tann, } \\
{ }^{\circ} \mathrm{C}\end{array}$ \\
\hline Fragment 1 (exons 3 to 13 ) & $\begin{array}{l}\text { ACACA-1-FW: 5'-CTG GAG CTG AAC CAG CAC TC-3' } \\
\text { ACACA-1-RV: 5'-CCC ATG GCA ATC TGG AGC TG-3' }\end{array}$ & 65.4 \\
\hline Fragment 2 (exons 11 to 24$)$ & $\begin{array}{l}\text { ACACA-2-FW: } 5{ }^{\prime} \text {-TGC TAC TCC AGC AGT ATT TGA ACA-3' } \\
\text { ACACA-2-RV: } 5^{\prime} \text {-ATC ACA CAA CAG CCT TCA TGT G-3' }\end{array}$ & 63.2 \\
\hline Fragment 3 (exons 22 to 38 ) & $\begin{array}{l}\text { ACACAF3-FW: } 5^{\prime} \text {-GTT TCC CAG CCA GCA GAT TG-3' } \\
\text { ACACAF3-RV: } 5^{\prime} \text {-AGT CAG TCC GGA CAT TTG TAT TG-3' }\end{array}$ & 60 \\
\hline Fragment 4 (exons 37 to 46 ) & $\begin{array}{l}\text { ACACA4N-FW: 5'-GTG GGC ACA GAA GTG ACA GA-3' } \\
\text { ACACA4N-RV: } 5^{\prime} \text {-GTT GTG CAT GAT CTG GAT GC-3' }\end{array}$ & 59.8 \\
\hline Exons 44 to 45 & $\begin{array}{l}\text { C5493TFW: 5'-GCC TAC GAC GAG ATC ATC ACC-3' } \\
\text { C5493TRV: 5'-TTT TCG ACC TGG ATG GTT CTC T-3' }\end{array}$ & 59 \\
\hline
\end{tabular}

${ }^{1}$ Primer locations with regard to sequence DQ370054 were: ACACA-1-RV (1298 to 1317), ACACA-2-FW (1102 to 1125), ACACA-2-RV (2861 to 2882), ACACAF3-FW (2722 to 2741), ACACAF3-RV (4303 to 4325), ACACA4N-FW (4151 to 4170), C5493TFW (5345 to 5365), C5493TRV (5424 to 5445). ACACA-1-FW and ACACA4N-RV and are external primers and, in consequence, they are not included in sequence DQ370054.

3 disconnected herds, were used for the experiment. Total milk produced in a single day was collected separately from each of these goats at least 4 times in a full lactation. Milk samples were transported on ice to the laboratory and to the experimental cheese factory. A near infrared spectrophotometer (NIR System 6250; Foss NIRsystems Inc., Silver Spring, MD) previously calibrated (Díaz et al., 1993; Angulo et al., 1996) was used to analyze protein, total $\mathrm{CN}, \alpha_{\mathrm{S}^{-}}$and $\alpha_{\mathrm{S} 2} 2-\mathrm{CN}$, fat, and DM content. Effective DM content was computed as the sum of fat and protein content. Somatic cells counts were measured in each sample by using a Fossomatic instrument (Foss Electric, Barcelona, Spain). An Optigraph instrument (Isebaert, Frepillon, France) was used to characterize milk-clotting capabilities (curd firming rate and curd firmness at $30 \mathrm{~min}$ ). Cheese was made with each individual milk sample following the traditional recipe used to make fresh goat cheese in Málaga (Ares, 1995). Cheese yield was measured $24 \mathrm{~h}$ after cheese elaboration.

\section{Sequencing and Genotyping of the Goat ACACA Gene}

The RNA isolation and cDNA synthesis procedures were performed as previously described (Amills et al., 2003). The coding sequence of the goat $A C A C A$ gene was amplified by using 4 primer pairs (Table 1 ). Polymerase chain reactions included $5 \mu \mathrm{L}$ of PCR buffer, $1.5 \mu \mathrm{L}$ (fragments 1, 3 and 4) or $2 \mu \mathrm{L}$ (fragment 2) of $\mathrm{MgCl}_{2}$ $(50 \mathrm{mM}), 1 \mu \mathrm{L}$ of dNTP $(5 \mathrm{~m} M), 0.5 \mu \mathrm{L}$ of each primer $(50 \mu M), 3 \mu \mathrm{L}$ of cDNA, and $0.25 \mu \mathrm{L}$ of Taq DNA polymerase (5 U/ $\mu L$, Ecogen S.R.L., Barcelona, Spain) in a final volume of $50 \mu \mathrm{L}$. The thermal profile consisted of 35 cycles of $94^{\circ} \mathrm{C}$ for $45 \mathrm{~s}$, annealing temperature (Table 1) for $30 \mathrm{~s}$, and $72^{\circ} \mathrm{C}$ for $1 \mathrm{~min}$.
Amplified products were sequenced in both directions in 18 individuals by using the BigDye Terminator v3.1 Cycle Sequencing kit (Applied Biosystems, Foster City, $\mathrm{CA}$ ) according to the manufacturer's instructions. Internal sequencing primers were ACACA2NEST-FW; 5'GGC GGA CTT CAT GAA TTT GC-3' (positions 1556 to 1575 of sequence DQ370054); ACACA2NEST-RV; 5'TTG GCT ATG ACA CAG CCA GG-3' (positions 2348 to 2367 of sequence DQ370054); ACACA3NEST-FW; 5'-CTA TCT TCC TAT CGG CTA TTG ACA TG-3' (positions 3222 to 3247 of sequence DQ370054), and ACACA4NEST-FW; 5'-CCT CCA GGC AGA ACT GAA AA$3^{\prime}$ (positions 4441 to 4460 of sequence DQ370054). Sequencing reactions were precipitated as follows: $1 \mu \mathrm{L}$ of $125 \mathrm{~m} M$ EDTA, $1 \mu \mathrm{L}$ of $3 M$ sodium acetate, $\mathrm{pH} 4.6$, and $25 \mu \mathrm{L}$ of $100 \%$ ethanol were added to $10 \mu \mathrm{L}$ of the sequencing reaction. This mixture was incubated for $15 \mathrm{~min}$ and centrifuged at $16,000 \times g$ for $15 \mathrm{~min}$. The DNA pellet was washed with $35 \mu \mathrm{L}$ of $70 \%$ ethanol and centrifuged at $16,000 \times g$ for $5 \mathrm{~min}$. The DNA pellet was dried at $90^{\circ} \mathrm{C}$ for $1 \mathrm{~min}$ and resuspended in $10 \mu \mathrm{L}$ of formamide. Sequencing reactions were analyzed in an ABI PRISM 3100 capillary electrophoresis device (Applied Biosystems).

The primers used for the amplification of the region containing the polymorphism (exons 44 to 45 ) are indicated in Table 1 (C5493TFW and C5493TRV). The PCR mixture included $5 \mu \mathrm{L}$ of PCR buffer, $2 \mu \mathrm{L}$ of $\mathrm{MgCl}_{2}$ $(50 \mathrm{mM}), 1 \mu \mathrm{L}$ of dNTP $(5 \mathrm{mM}), 0.5 \mu \mathrm{L}$ of each primer $(50 \mu \mathrm{M}), 3 \mu \mathrm{L}$ of cDNA, and $0.25 \mu \mathrm{L}$ of Taq DNA polymerase ( $5 \mathrm{U} / \mu \mathrm{L}$, Ecogen S.R.L.) in a final volume of 50 $\mu \mathrm{L}$. The thermal profile consisted of 35 cycles of $94^{\circ} \mathrm{C}$ for $45 \mathrm{~s}, 59^{\circ} \mathrm{C}$ for $30 \mathrm{~s}$, and $72^{\circ} \mathrm{C}$ for $1 \mathrm{~min}$. The PCR products were purified by using the ExoSAP-IT kit (Amersham Biosciences Europe GmbH, Barcelona, Spain) and typed with the SnaPshot ddNTP Primer Extension 
kit (Applied Biosystems). The extension primer used in the typing procedure was 5'-CAT TGG GAT TGG GGC TTA CCT-3' (positions 5389 to 5409, with regard to sequence DQ370054).

\section{Association Analysis with Milk Traits}

Statistical analyses were performed using the mixed linear model procedure as implemented in the SAS statistical software (SAS Institute, 2002). Following Littell et al. (1998), a mixed model, $\mathrm{Y}=\mathrm{X} \beta \_+\mathrm{ZU}+\mathrm{e}$, was used, where $\beta$ is the vector of fixed parameters (values of levels of fixed factors: genotype, G; herd-year-season, HYS; parity number, NP; number of kids born, NK; and month of sampling, $\mathrm{MS}$ ); $\mathrm{X}$ is the incidence matrix for these effects; $U$ is the vector of random animal effects; $\mathrm{Z}$ is the incidence matrix for these effects, and $\mathrm{e}$ is a vector of the residual random errors, assumed normally distributed with mean $\mathrm{E}(\mathrm{e})=0$ and variance $\mathrm{V}(\mathrm{e})=\mathrm{R}$. In this case, there existed repeated measures of the variable within goat that were assumed to be correlated. Therefore, the REPEATED instruction of the mixed linear model procedure of SAS was implemented with the CS option, which defines a compound symmetric structure of $R$. This structure assumes that all repeated measures have the same variance, and that all pairs of measures on the same animal have the same correlation. Thus, the covariance between repeated measures is only due to the individual contribution and not to the fact that they were taken from the same individuals at different time points. Linear combinations of parameters values $L^{\prime} \beta$ (L being a vector of coefficients) and their corresponding variance $\mathrm{V}\left(\mathrm{L}^{\prime} \beta\right)$, estimated with this model, allow for testing differences between genotype means using $t$ distribution. The Bonferroni correction for multiple comparisons was applied. The Bonferroni correction yielded a significance threshold of $P<0.007$. Accordingly, associations with a $P$ value ranging from 0.007 to 0.05 were classified as statistical tendencies.

\section{RESULTS AND DISCUSSION}

Most of the coding sequence of the goat ACACA gene was amplified and sequenced. The cDNA sequence was $5.5 \mathrm{~kb}$ ( $78 \%$ of the coding sequence) and partially encompassed exons 3 to 46 (GenBank accession no.: DQ370054). This partial sequence encoded a protein of 1,832 AA. A BlastP search of the GenBank database revealed that the translated ACACA cDNA sequence displayed 99\% AA identity with its ovine and bovine $A C A C A$ orthologous sequences.

Several structural motifs typical of this enzyme were identified in the goat ACACA sequence by using

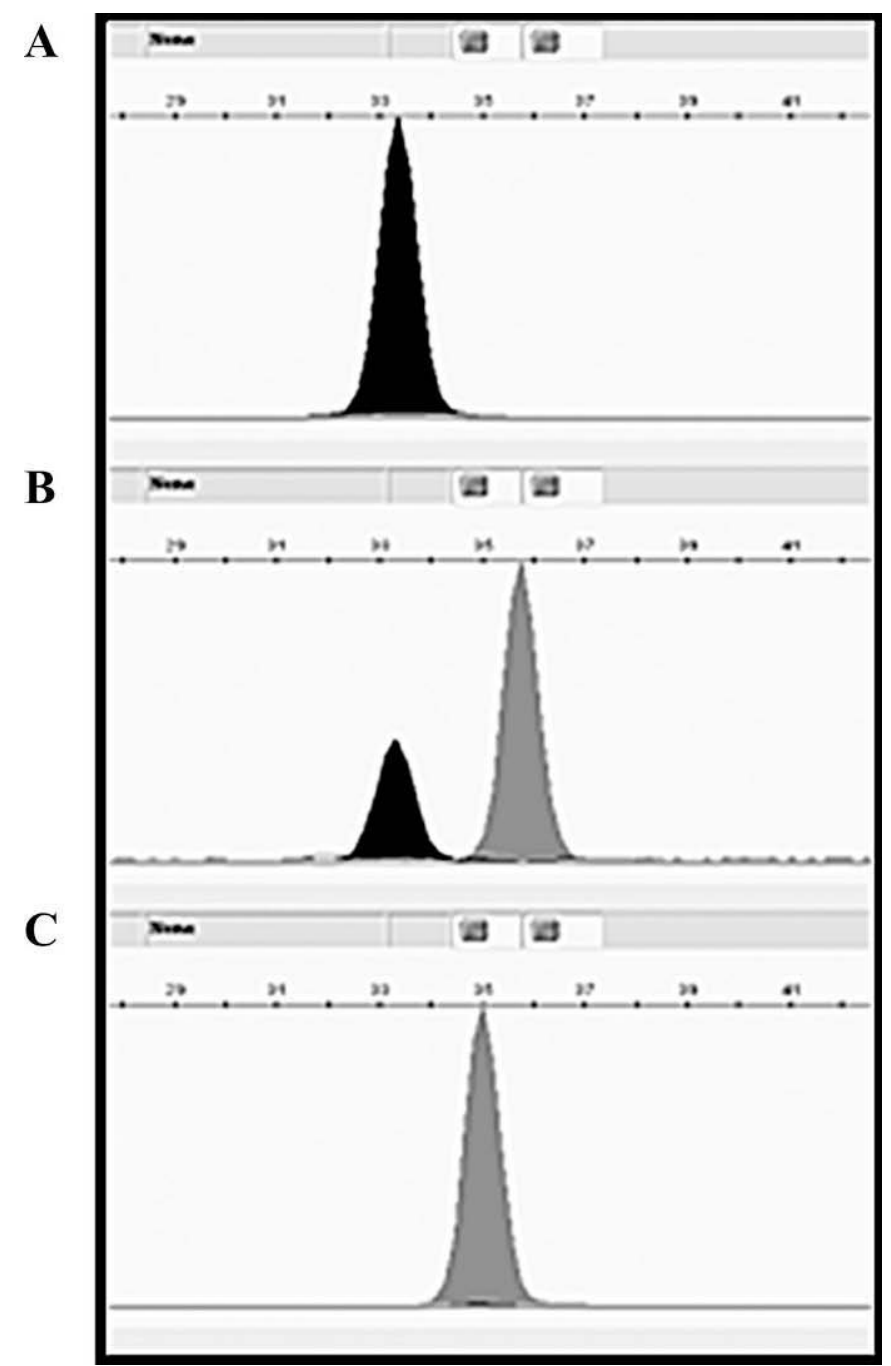

Figure 1. Electropherogram of the C5493T single nucleotide polymorphism in the acetyl-coenzyme A carboxylase $\alpha$ (ACACA) gene analyzed with the Gene Mapper software. The black (lane a), blackgray (lane b), and gray (lane c) peaks correspond to the CC, CT, and TT genotypes, respectively.

the ProSite software (http://www.expasy.org/prosite). These motifs include: 1) the biotinyl/lipoyl domain, which contains a biotin group covalently linked to a Lys residue; 2) the biotin carboxylation domain that catalyzes the ATP-dependent carboxylation of this biotin group; and 3) the carboxyl transferase domain that catalyzes the transfer of the carboxyl group from biotin to acetyl-CoA to produce malonyl-CoA.

The alignment of $A C A C A$ sequences from 18 goats belonging to the Murciano-Granadina breed allowed the detection of one silent C5493T polymorphism at exon 45 of the ACACA gene (position 1 is the translational start of sheep sequence X80045). We optimized a primer extension protocol for genotyping the C5493T SNP in 200 Murciano-Granadina goats (Figure 1). This 
Table 2. Genotypic frequencies of the ACACA C5493T single nucleotide polymorphism in 4 breeds of goat

\begin{tabular}{lllll}
\hline & \multicolumn{4}{c}{ Breed } \\
\cline { 2 - 5 } & $\begin{array}{l}\text { Murciano- } \\
\text { Granadina } \\
\text { Genotype }\end{array}$ & $\begin{array}{l}\text { Majorera } \\
(\mathrm{n}=200)\end{array}$ & $\begin{array}{l}\text { Malagueña } \\
(\mathrm{n}=29)\end{array}$ & $\begin{array}{l}\text { Teramana } \\
(\mathrm{n}=15)\end{array}$ \\
\hline CC & 0.644 & 0.533 & 0.379 & 0.66 \\
CT & 0.288 & 0.467 & 0.483 & 0.34 \\
TT & 0.068 & 0.000 & 0.138 & 0.000 \\
\hline
\end{tabular}

analysis confirmed that this polymorphism is segregating in 3 Murciano-Granadina herds $(\mathrm{n}=200)$ for which milk traits have been recorded (Table 2). Moreover, a representative sample of 59 goats belonging to 3 different breeds was analyzed (Table 2). Despite the small sample sizes, this SNP was segregating in the 4 breeds at variable frequencies. The analysis also showed that the $\mathrm{C}$ allele was more abundant than the $\mathrm{T}$ allele in most breeds, with frequencies of the $\mathrm{C}$ allele ranging from 0.62 to 0.83 . The analysis of 3 biallelic SNP located in the PIII promoter of the ACACA gene in several sheep breeds revealed a similar picture: Any of these mutations was breed-specific and the most abundant alleles had frequencies between 0.58 and 1.00 (Moioli et al., 2005).

An association analysis was performed in 130 Murciano-Granadina goats with the objective of investigating the existence of any relationship between the found SNP and milk composition (Table 3). A suggestive association was found among ACACA C5493T genotypes with regard to milk fat $(P<0.05)$, lactose content $(P<$ $0.05)$, and SCC $(P<0.05)$, although these differences did not reach statistical significance after the Bonferroni correction. These associations might be explained by the fact that the C5493T SNP is a true causal mutation with pleiotropic effects or because this polymorphism is linked to other polymorphisms influencing the aforementioned traits. This latter interpretation is favored, because the mutation that was genotyped is synonymous and, as a consequence, it is not expected to produce a structural change in the ACACA enzyme. Moreover, this mutation is not placed in a location (such as the promoter region or the $3^{\prime}$ untranslated region) that might affect gene expression.

Undoubtedly, the complete sequencing of the caprine ACACA gene, which might encompass about $330 \mathrm{~kb}$, would be fundamental to ascertaining if there are additional SNP linked to the SNP found in this study, and if these additional SNP are good candidates for having a structural or regulatory role. Acetyl-coenzyme A carboxylase $\alpha$ is the rate-determining enzyme in lipogenesis and we have identified a suggestive association between the C5493T polymorphism and milk fat content. This finding suggests the existence of another uncharacterized SNP located in the ACACA transcription unit, or in its vicinity, with effects on enzyme expression or function. The suggestive association between the $A C A C A$ genotype and lactose content is also interesting because the synthesis of this carbohydrate and lipogenesis are closely related processes. Glucose is a precursor in the synthesis of lactose and glycerol-3-phosphate, which is necessary for the synthesis of triglycerides and, more importantly, when entering into the pentose shunt, yields the NADPH that will be used in fatty acid biosynthesis to provide reductor power. However, the CT genotype was found to be associated with higher levels of milk fat and lactose when compared with the CC genotype. This finding is rather paradoxical if we assume that both pathways compete for the same precursor (glucose), thus supporting our conclusion that the associations we have found are explained by the

Table 3. Association analysis between ACACA C5493T genotypes and goat milk traits

\begin{tabular}{lcrr}
\hline & \multicolumn{2}{c}{ Contrast between ACACA C5493T genotypes ${ }^{1}$} \\
\cline { 2 - 4 } Trait & \multicolumn{1}{c}{ CC-CT } & \multicolumn{1}{c}{ CC-TT } & \multicolumn{1}{c}{ CT-TT } \\
\hline Milk yield, kg & $0.15(0.11)$ & $0.004(0.18)$ & $-0.15(0.19)$ \\
Milk fat content, \% & $-0.40(0.17)^{*}$ & $0.11(0.27)$ & $0.51(0.29)$ \\
Milk protein content, \% & $0.056(0.07)$ & $-0.05(0.11)$ & $-0.10(0.12)$ \\
Milk lactose content, \% & $-0.10(0.04)^{*}$ & $0.01(0.06)$ & $0.11(0.07)$ \\
$\alpha_{\text {S1-CN content, g/kg }}$ Dry weight basis, \% & $-0.30(0.41)$ & $-0.48(0.63)$ & $-0.18(0.68)$ \\
Log SCC & $-0.47(0.33)$ & $0.37(0.54)$ & $0.84(0.58)$ \\
Curd firming rate, V & $0.02(0.02)$ & $-0.06(0.04)$ & $-0.08(0.04)^{*}$ \\
Curd firmness at 30 min, V & $0.24(0.67)$ & $-0.36(1.12)$ & $-0.60(1.18)$ \\
Serum fat content, \% & $0.63(0.89)$ & $-0.37(1.48)$ & $-1.00(1.55)$ \\
Serum protein content, \% & $0.10(0.12)$ & $-0.07(0.19)$ & $-0.17(0.20)$ \\
Serum lactose content, \% & $-0.01(0.05)$ & $-0.14(0.08)$ & $-0.13(0.09)$ \\
\hline
\end{tabular}

${ }^{1}$ Standard errors of differences among genotypes are indicated in parentheses.

${ }^{2}$ Decimal logarithm of SCC value/1,000.

$* P<0.05$. 
presence of a closely linked mutation(s) located in the $A C A C A$ gene or in a neighboring locus.

In summary, the structural characterization of most of the goat $A C A C A$ coding sequence was reported and a SNP that shows a suggestive association with milk composition was described. Sequencing of the complete goat $A C A C A$ gene combined with the performance of association studies using larger, diverse populations are needed to achieve a reliable picture of the variability of this locus and its influence on milk fat and other traits related to milk composition. Moreover, the implementation of an allele-specific quantitative PCR assay to measure the levels of mRNA expression of the ACACA C5493 and T5493 alleles in the mammary gland of heterozygous individuals would give valuable insights into the molecular basis of the associations that we have found.

\section{ACKNOWLEDGMENTS}

This work has been funded with a grant of the Spanish Ministry of Science and Technology (AGL200204304-C03-02 GAN) and in part by a research scholarship to Bouabid Badaoui from CIHEAM (Instituto Agronómico Mediterráneo de Zaragoza, Spain).

\section{REFERENCES}

Amills, M., N. Jimenez, D. Villalba, M. Tor, E. Molina, D. Cubilo, C. Marcos, A. Francesch, A. Sanchez, and J. Estany. 2003. Identification of three single nucleotide polymorphisms in the chicken insulin-like growth factor 1 and 2 genes and their associations with growth and feeding traits. Poult. Sci. 82:1485-1493.

Angulo, C., M. Amills, J. L. Ares, I. Jiménez, J. Jordana, A. Sánchez, and J. M. Serradilla. 1996. Genetics of caseins and its relation with yield, composition and cheese making of milk in Spanish breeds of goats. Proc. 47th Annu. Mtg. EAAP, Lillehammer, Norway. EAAP, Rome, Italy.

Ares, J. L. 1995. Research on the cheese sector in Andalusia: Traditional technologies and social and economic aspects. $\mathrm{PhD}$ Thesis. University of Córdoba, Spain.

Barber, M. C., N. T. Price, and M. T. Travers. 2005. Structure and regulation of acetyl-CoA carboxylase genes of metazoa. Biochim. Biophys. Acta 1733:1-28.

Barber, M. C., and M. T. Travers. 1995. Cloning and characterisation of multiple acetyl-CoA carboxylase transcripts in ovine adipose tissue. Gene 154:271-275.

Barber, M. C., and M. T. Travers. 1998. Elucidation of a promoter activity that directs the expression of acetyl-CoA carboxylase with an alternative $\mathrm{N}$-terminus in a tissue restricted fashion. Biochem. J. 333:17-25.

Cronan, J. E., Jr., and G. L. Waldrop. 2002. Multi-subunit acetylCoA carboxylases. Prog. Lipid Res. 41:407-435.

Díaz, E., A. Muñoz, A. Alonso, and J. M. Serradilla. 1993. Near infrared calibration for goat's milk components protein, total casein, $\alpha$ s- $^{-}, \beta$-, and $\kappa$-caseins, fat and lactose. J. Near Infrared Spectrosc. 1:141-146.

Littell, R. C., P. R. Henry, and C. B. Ammerman. 1998. Statistical analysis of repeated measures data using SAS procedures. J. Anim. Sci. 76:1216-1231.

Mao, J., S. Marcos, S. K. Davis, J. Burzlaff, and H. M. Seyfert. 2001. Genomic distribution of three promoters of the bovine gene encoding acetyl-CoA carboxylase alpha and evidence that the nutritionally regulated promoter I contains a repressive element different from that in rat. Biochem. J. 358:127-135.

Moioli, B., F. Napolitano, L. Orru, and G. Catillo. 2005. Single nucleotide polymorphism detection in promoter III of the acetyl-CoA carboxylase- $\alpha$ gene in sheep. J. Anim. Breed. Genet. 122:418-420.

Ramsay, R. R., R. D. Gandour, and F. R. van der Leij. 2001. Molecular enzymology of carnitine transfer and transport. Biochim. Biophys. Acta 1546:21-43.

SAS Institute. 2002. SAS User's guide: Statistics. Version 9.1 ed. SAS Inst., Inc., Cary, NC.

Travers, M. T., and M. C. Barber. 1993. Isolation of a goat acetylCoA carboxylase complementary DNA and effect of milking frequency on the expression of the acetyl-CoA carboxylase and fatty acid synthase genes in goat mammary gland. Comp. Biochem. Physiol. 105:123-128. 